ISSN 1112-9867

Available online at

http://www.jfas.info

\title{
SEISMIC BEHAVIOR OF CONXL CONNECTIONS IN CONCRETE FILLED STEEL TUBE COLUMNS (CFT)
}

\author{
A. Seyfi Azar, T. Moradi Shaghaghi* \\ Department of Civil Engineering, Tabriz Branch, Islamic Azad University, Tabriz, Iran
}

Received: 18 May 2016 / Accepted: 14 December 2016 / Published online: 01 January 2017

\begin{abstract}
Steel box-shaped columns are suitable structural members for structures with moment frames in two directions, but plate connections have several construction problems, including inaccessibility of inside of columns, welding difficulties, etc. ConXL connections are the new proposed details to reduce these problems. This connection consists of collar flange, collar corner, and collar web extension. In this paper, the seismic behavior of these types of connections is investigated using the numerical method. For this purpose, three samples of ConXL connections without concrete filler, with concrete filler and with concrete filler and stiffener plates inside the column were studied using Abaqus software. The results demonstrated that the ductility of the ConXL connection without concrete filler is more than the two other samples, while the strength of this connection is less than the strengths of the two other samples. It was observed that utilizing stiffener plate inside the column has no significant effect on the strength of the connection.
\end{abstract}

Keywords: ConXL moment connection; collar; concrete filled steel tube (CFT); ductility; stiffener plate.

Author Correspondence, e-mail: ta.moradi@iaut.ac.ir

doi: http://dx.doi.org/10.4314/jfas.v9i1.15

\section{INTRODUCTION}

Design of beam-column connections is important in steel structures with tube columns. Box-shaped columns are used as a component of special moment frames of mid-rise and 
high-rise structures in locations with high seismic risk, like American and Asian countries, and Iran. These tube sections are often in the form of rolled sections such as RHS, HSS, etc., or sections constructed from welded plates $[1,8]$.

The significant bending strength and stiffness around each axis has made box-shaped sections more effective than conventional wide flange sections as beam and column members. Moreover, high lateral-torsional stiffness and inconsiderable distortion reduce the need to lateral bracing and prevent the strength loss which is usually caused by column rotation due to lateral-torsional buckling [2,3,7].

Ductility and high energy loss, due to negligible effects of local buckling and having post-buckling strength, make the box sections appropriate as column members in earthquake resistant moment frames. Also, materials are highly used in tube columns while the cost of painting and maintaining surfaces is low [2].

Despite all the above mentioned advantages, there are limitations due to the box shape of tube columns such as inaccessibility of columns inside for welding and construction of continuity plates, difficulties of weld inspection, and high construction costs. On the other hand, existence of two parallel webs in tube columns leads to different behavior in comparison with the other wide flange columns [3].

These factors have caused wide investigations around the world in the field of proposing an appropriate shape and studying the behavior of box columns connections in order to reduce construction costs and to efficiently transfer loads to columns through the connections. Different researchers have studied in this field and many schemes have been proposed. One of these new connections, which is accepted in AISC as a prequalified connection, is ConXL connection. This connection was first proposed by Robert J. Simmons. The purposes of proposing this connection include industrialization, eliminating on-site welding, increasing the safety, simplification and increasing speed of construction in high-rise structures with box-shaped columns. The connection is proposed based on Simmons theory which makes its implementation as easy as dragging and dropping connection at the collar [4]. 


\section{NUMERICAL ANALYSIS OF CONXL CONNECTION SAMPLES}

\subsection{Configuration and load distribution mechanism}

A ConXL moment connection is shown in Figure 1. This connection consists of HSS40 40 square box columns or boxes constructed from plates and column collars (a collar at each corner of the column). Collars, which are connected to columns by welding bands, are composed of three components including: Collar Corner Top (CCT), Collar Corner Bottom (CCB), and Collar Corner Middle (CCM). Wide flange beams have collars at their two ends naming Collar Flange Top (CFT) and Collar Flange Bottom (CFB). If the beam depth is greater than 460mm, Collar Web Extension (CWX) is used only at the beam-to-column connection (Figure 2).

A set of diagonal pre-tensioned high strength bolts (with an angle of $45^{\circ}$ ) have been used to connect collar flange top and collar flange bottom to collar corners on four edges of the column. Thus, a rigid diaphragm is formed around the column [5].

All of top and bottom flange collars are connected to the beam by groove welding with full penetration. Collar web extensions are connected to beams by corner welding. This welding is also used to connect collar corners to columns, and collar corners are connected to each other by groove welding. All these connections have been prepared in factory and pieces are only assembled at the workplace [5].

Load distribution mechanism in this connection is through transferring forces caused by bending moments in the beam flange by means of full penetration groove welding to the collar flanges. In this case, the collar flange transmits compressive force of the beam flanges to collar corners by means of collar flange curvature and support contact caused by sloped surfaces of collars. The other collar flange transfers tensile force caused by bending to pre-tensioned bolts. The collar bolts distribute these forces all over the collars of perpendicular flanges. Then, these forces pass through the rear collars bolts on the opposite side of the column and are transferred to all sides of the column which are a combination of load-bearing contact area and corner welding connecting corner collars to the column. Moreover, if the column is filled with concrete, a part of these forces is transferred to the filler concrete in contact with the column wall [5]. 


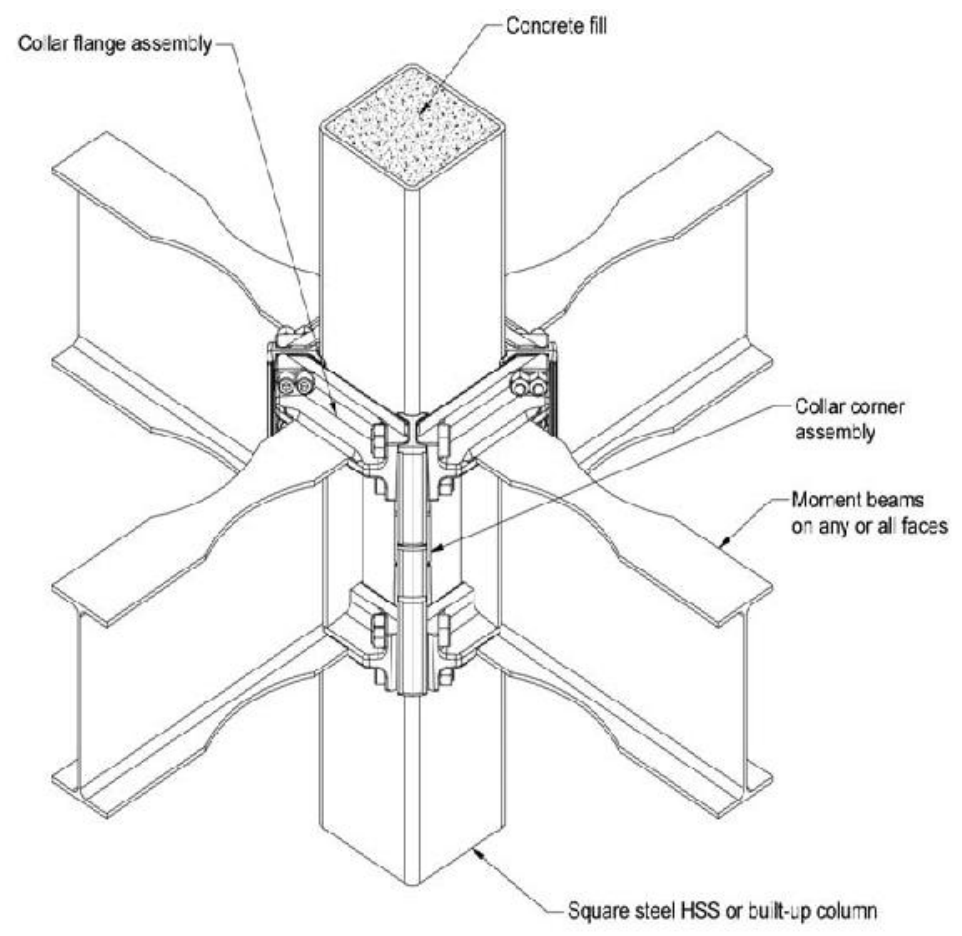

Fig.1. Schematic of the ConXL connection [5]

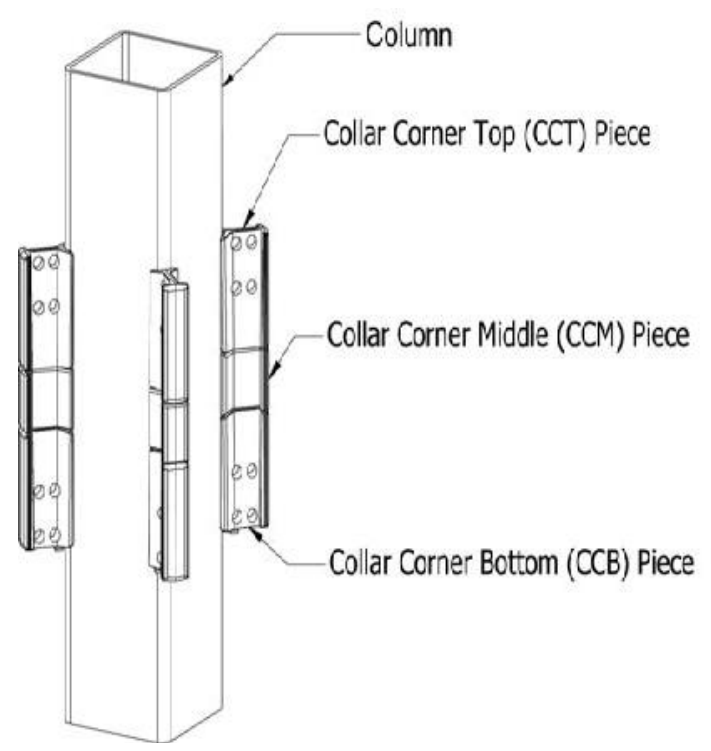




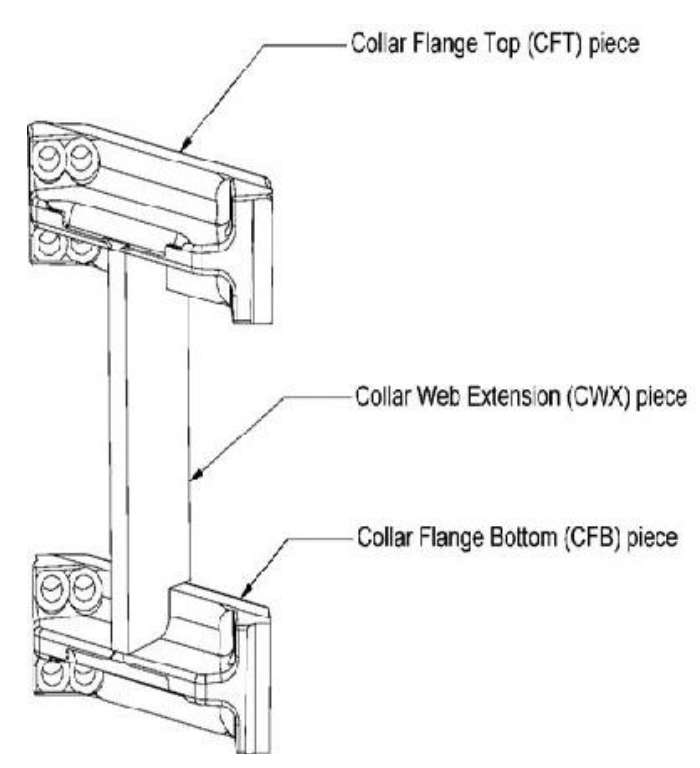

Fig.2. Geometry and details of ConXL connection [5]

\subsection{Material Properties of ConXL connection samples}

The material properties of beams and columns were assumed according to ASTM A36 standard, with the yield stress of $280 \mathrm{Mpa}$ and the ultimate stress of $480 \mathrm{Mpa}$. The material properties of collars were considered based on STM A572 GR50 standard, with the yield stress of 390Mpa and the ultimate stress of 510Mpa.

High strength bolts were used according to ASTM A574 standard with the yield stress of $1050 \mathrm{Mpa}$, the ultimate stress of $1150 \mathrm{Mpa}$, the ultimate strain of 0.2 , Poisson's ratio of 0.3 and Young's modulus of $2 \times 105 \mathrm{Mpa}$.

Compressive strength of concrete filler used in some of the samples was equal to $24 \mathrm{Mpa}$ with Poisson's ratio of 0.25 , Young's modulus of $2 \times 104 \mathrm{Mpa}$, and the ultimate compressive strain of 0.003. The properties of the stiffener plate were assumed based on ASTM A36 standard, with the yield stress of $280 \mathrm{Mpa}$, the ultimate stress of $480 \mathrm{Mpa}$, the ultimate strain of 0.2 , Poisson's ratio of 0.3 , and Young's modulus of $2 \times 105 \mathrm{Mpa}$, as shown in Table (1). 
Table 1. The material properties of the studied samples

\begin{tabular}{llcc}
\hline \multicolumn{1}{c}{ Section type } & \multicolumn{1}{c}{ Standards } & F $_{\mathbf{y}}(\mathbf{M p a})$ & $\mathbf{F}_{\mathbf{u}}(\mathbf{M p a})$ \\
\hline BOX - Column- $40 \times 40 \times 1.25$ & ASTMA36 & 280 & 480 \\
$63 \times 23$ W -Collar web extension & ASTMA36 & 280 & 480 \\
Collar system set & ASTMA36-50GR & 390 & 510 \\
Bolt diameter (3cm) & ASTMA574 & 1050 & 1150 \\
Stiffener plate & ASTMA36 & 280 & 480 \\
\hline
\end{tabular}

Table 2. Sizes of the components of ConXL connection of the modeled samples

\begin{tabular}{|c|c|c|c|c|c|}
\hline Section type & $\begin{array}{c}\text { Web } \\
\text { thickness } \\
\text { tw (cm) }\end{array}$ & $\begin{array}{c}\text { Flange } \\
\text { thickness tf } \\
(\mathrm{cm})\end{array}$ & $\begin{array}{c}\text { Web } \\
\text { height h } \\
(\mathrm{cm})\end{array}$ & $\begin{array}{c}\text { Flange } \\
\text { breadth } \\
\text { b }(\mathbf{c m})\end{array}$ & $\begin{array}{c}\text { Length } \\
\text { of piece } \\
(\mathrm{cm})\end{array}$ \\
\hline $\begin{array}{l}\text { BOX -column } \\
40 \times 40 \times 1.25\end{array}$ & 1.25 & 1.25 & 40 & 40 & 300 \\
\hline W63× 23 -Beam & 1.054 & 1.486 & 60.2 & 22.784 & 150 \\
\hline Collar system set & \multicolumn{5}{|c|}{$\begin{array}{l}\text { Various dimensions of the collar pieces were modeled } \\
\text { based on the typical maps provided in AISC-358S1-11. }\end{array}$} \\
\hline $\begin{array}{l}\text { Bolt diameter } \\
\quad(3 \mathrm{~cm})\end{array}$ & - & - & - & - & 16 \\
\hline Stiffener plate & - & 1.2 & - & 15 & 37.5 \\
\hline
\end{tabular}

\subsection{Samples modeled in ABAQUS}

In order to achieve the main purpose of the study, three samples of ConXL connection including the sample with no concrete filler, ConXL connection with concrete filler, and ConXL connection with concrete filler and stiffener plate inside the column along the top flange of the beam were used. Size of all components was according to Table (2) and these components are shown in Figure 3. In all samples, the four-node solid three-dimensional elements with three degrees of freedom were used. Mesh of similar samples is demonstrated in Figure 4. In order to apply contact stress between all pieces and surfaces in contact with 
each other, Surface-to-Surface option has been used with Coulomb friction coefficient of 0.1 in software and the stiffness effect was considered too[6].

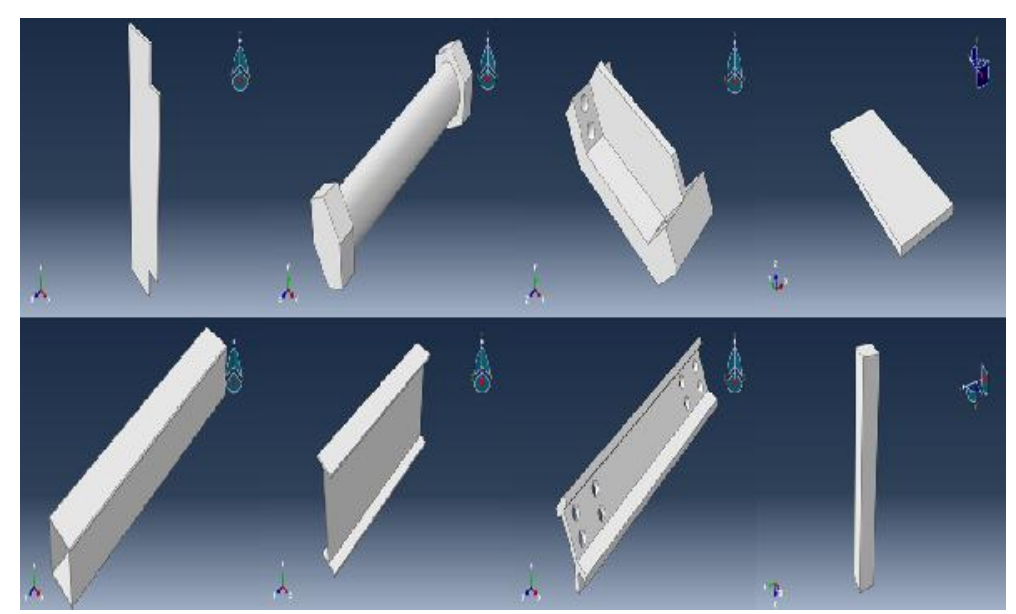

Fig.3. Components modeled in the analysis

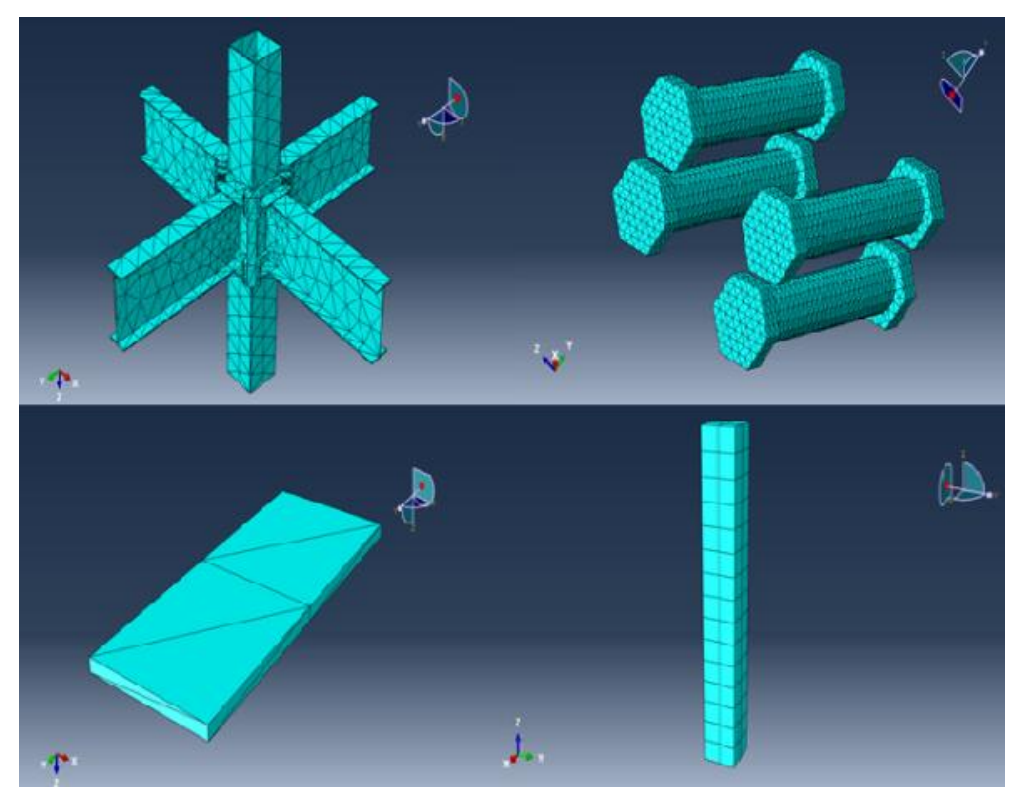

Fig.4.The mesh used in modeled components

\section{LOADING SCHEME}

All connections were investigated using dynamic explicit analysis and considering the loading model shown in Figure 5, in which $\mathrm{H}$ is the column length and $\mathrm{L}$ is the moment arm imposed to the connection under loading 1 and 2 as shown in Figure 6 and 7. Loadings were imposed as force on the end of the moment arm. Loading type 1 was used to obtain the non-linear 
static analysis curves and loading type 2 was used to obtain the hysteresis curves.

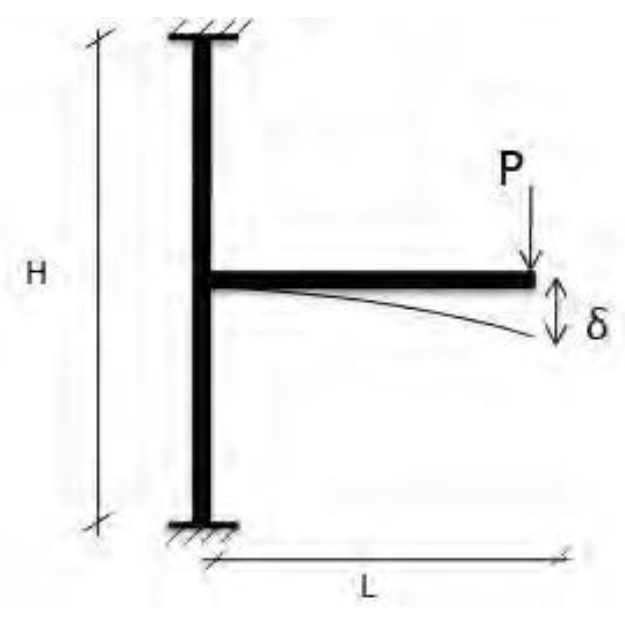

Fig.5. Models loading

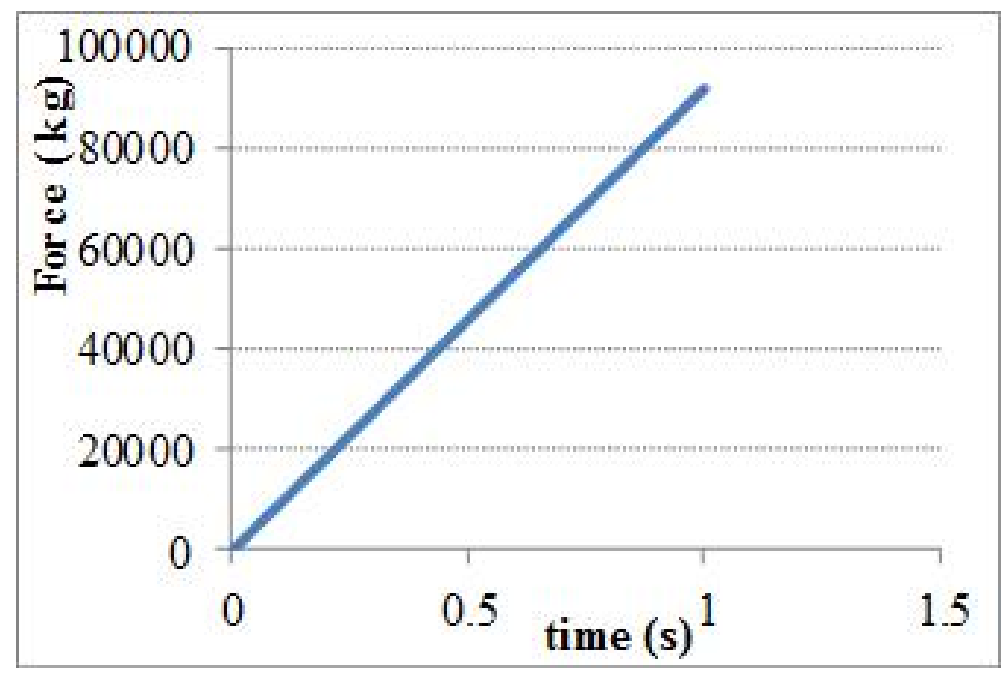

Fig.6. Loading scheme 1

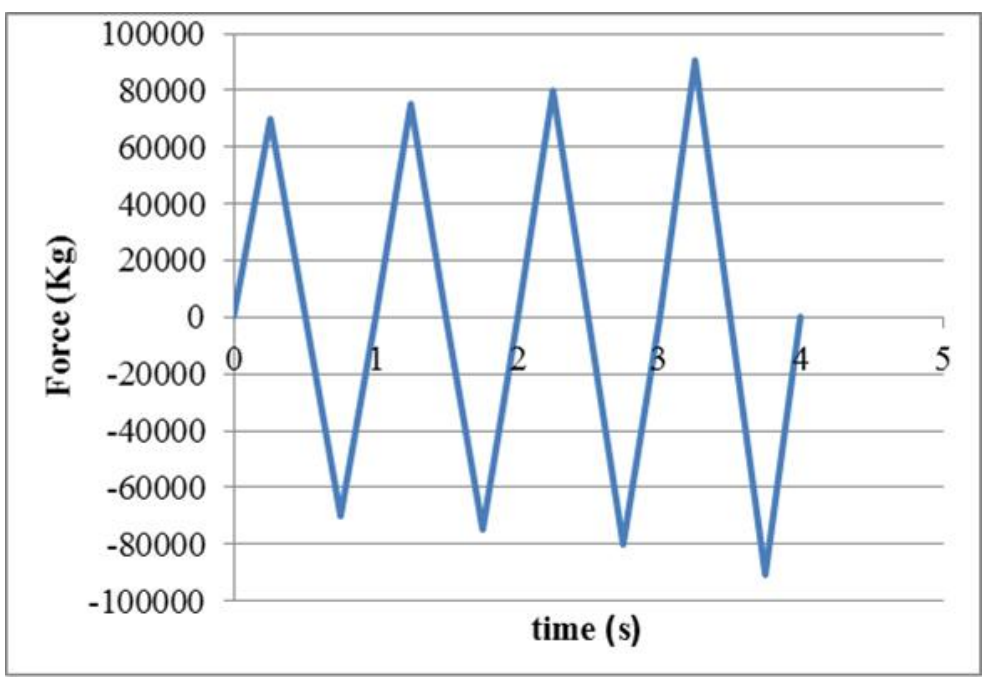

Fig.7. Loading scheme 2 


\section{RESULTS OF NUMERICAL ANALYSIS}

All three ConXL connections were imposed to both increasing cyclic and linear loadings, and then pushover and hysteresis curves were plotted as shown in Figures 9 and 10. According to the analysis results, all three samples were almost elastic until the displacement of the end of beam reached to amount of $0.7 \mathrm{~cm}$, and they entered into the plastic phase by increasing the load. In all three samples, the plasticity distribution of the beams increased by loading in top and bottom flange of the beam and enhanced toward the center of web. In this level, all parts of the collar and column systems demonstrated almost elastic behavior. By increasing the load, buckling started in beams and flanges and continued until the end of loading. In this level, the collar system remained in elastic likewise. In columns stress started from the connection of collar corners up to the middle of the web on the both sides. By increasing the load, stress increased in the column, but no buckling occurred at any point (Figure 8).

According to the force-displacement pushover curve of the ConXL connection without concrete filler (vide Figure 9) it is observed that this connection had almost elastic behavior up to the load of 65 tons and the displacement of the end of beam equal to $0.7 \mathrm{~cm}$, and then it entered into the plastic phase by increasing the load and displacement. The ultimate resistance of this connection was equal to 87 tons in which failure occurred. The ultimate displacement was equal to $2.73 \mathrm{~cm}$. Moreover ductility of the sample was equal to $\mu=\frac{\delta_{\max }}{\delta_{Y}}=3.9$.

It was observed from the force-displacement pushover curve of the ConXL connection with concrete filler (see Figure 9) that this connection remained almost elastic up to the load equal to amount of 70 tons and the beam displacement of $0.76 \mathrm{~cm}$, and its behavior non- elastic and entered into the plastic phase by increasing the force and displacement. The maximum resistance the mentioned connection was equal to 90tons. The ultimate displacement was equal to $2.53 \mathrm{~cm}$. Also the ductility of the sample was equal to $\mu=\frac{\delta_{\max }}{\delta_{Y}}=3.3$.

On the other hand the force-displacement pushover curve of the ConXL connection with concrete filler and stiffener plate (see Figure 9) showed that this connection had elastic behavior up to the load and displacement similar to the connection with concrete filler and equal to 70 tons and $0.76 \mathrm{~cm}$ respectively. The maximum resistance of this connection was 
equal to 92 tons. Moreover the ultimate displacement was equal to $2.38 \mathrm{~cm}$. And ductility of the sample was equal to $\mu=\frac{\delta_{\max }}{\delta_{Y}}=3.13$.

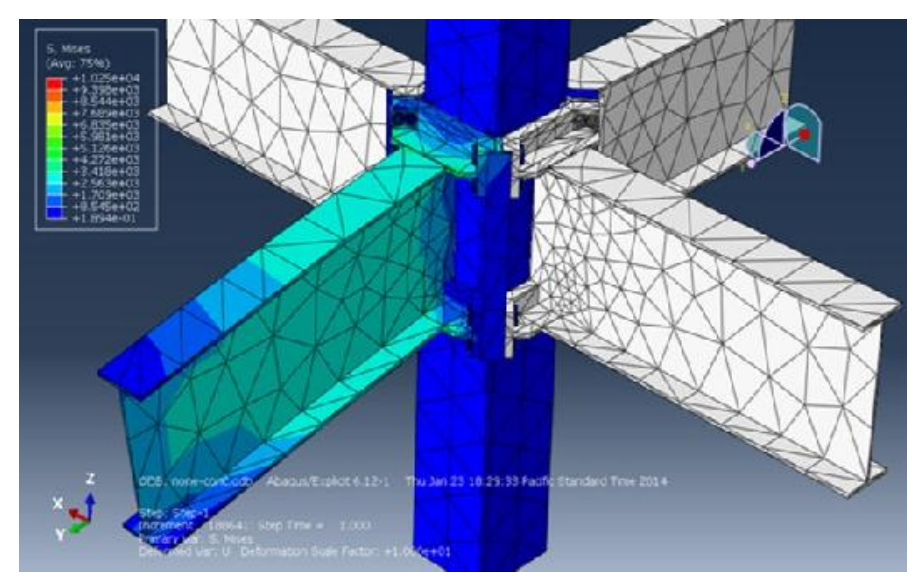

(A)

Connection without concrete filler and stiffener plate

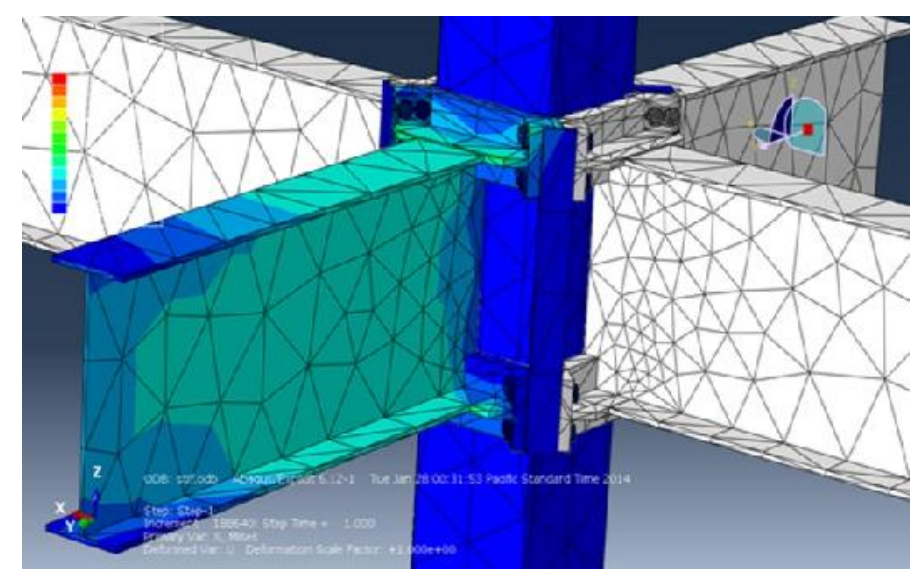

(B)

Connection with concrete filler and stiffener plate

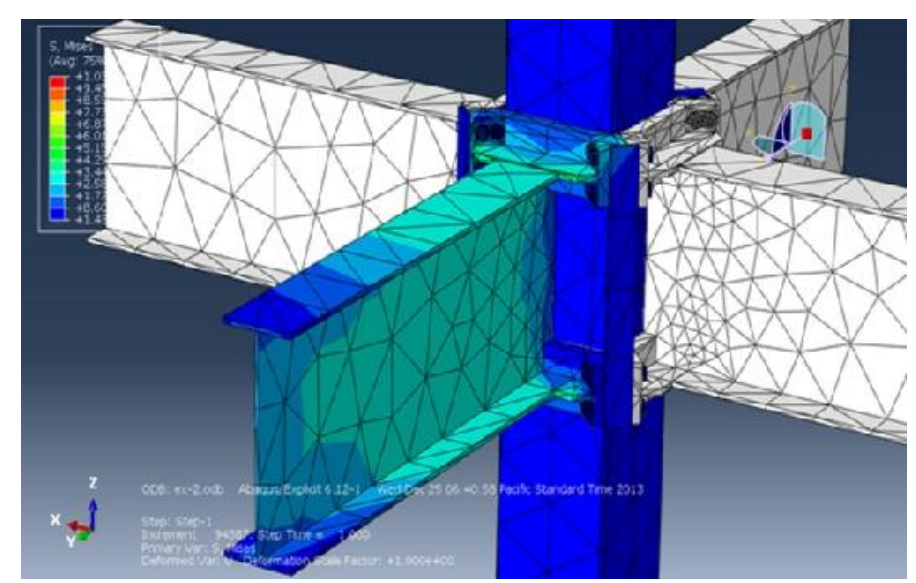

(C)

Connection with concrete filler 


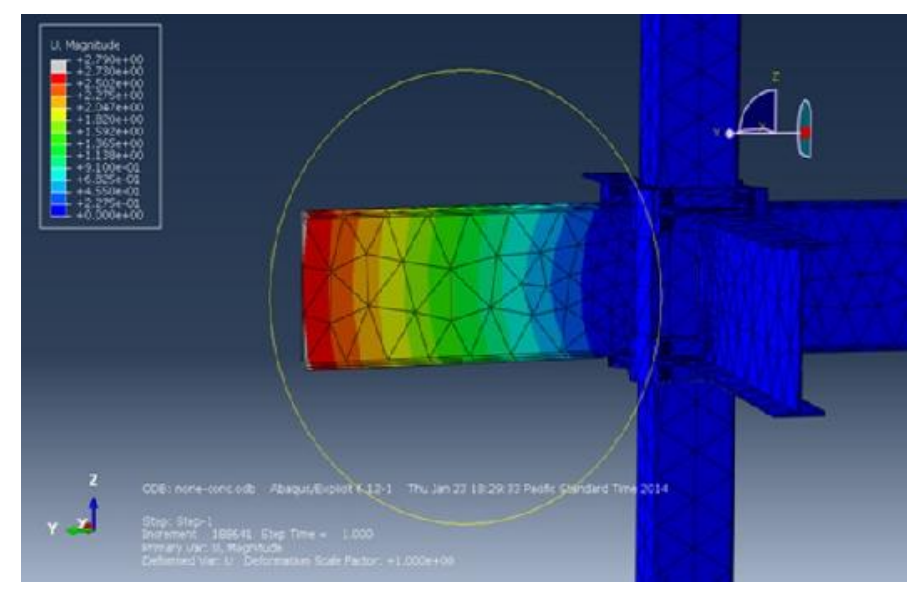

(D)

Fig.8. A, B, C) Von Mises stress distribution in the samples; D) Displacement in the connection with concrete filler

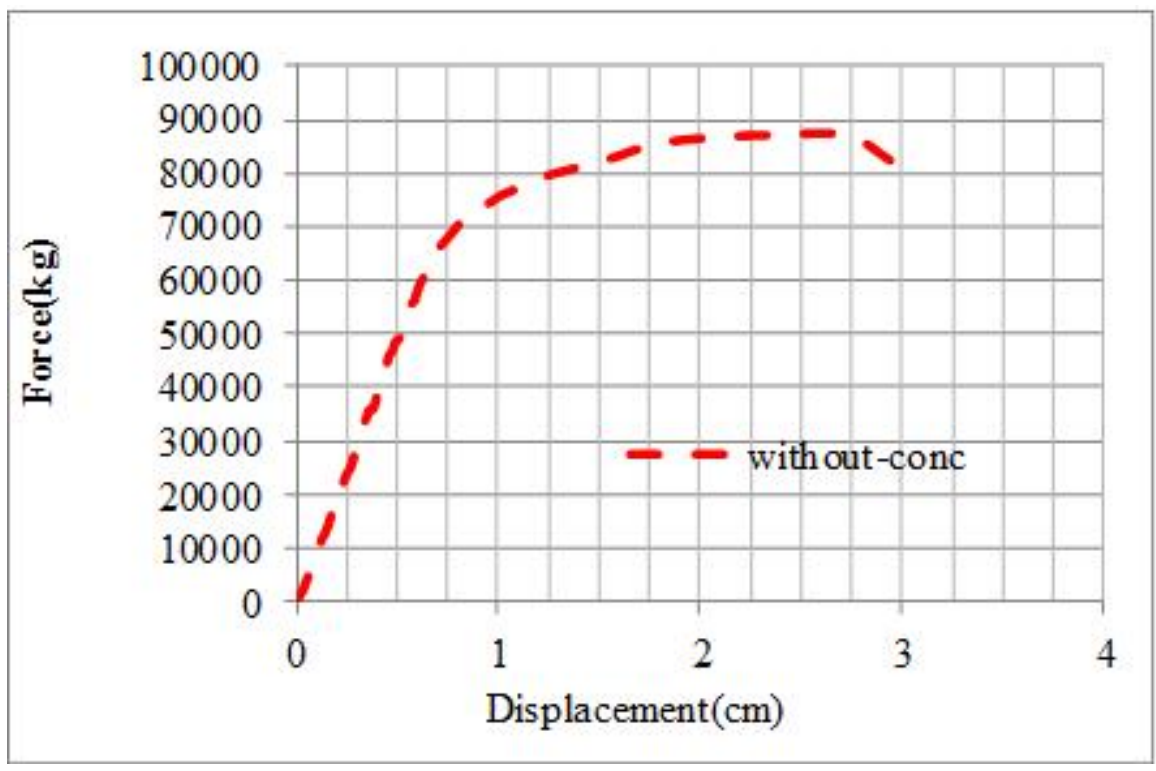

A) Sample without filler concrete 


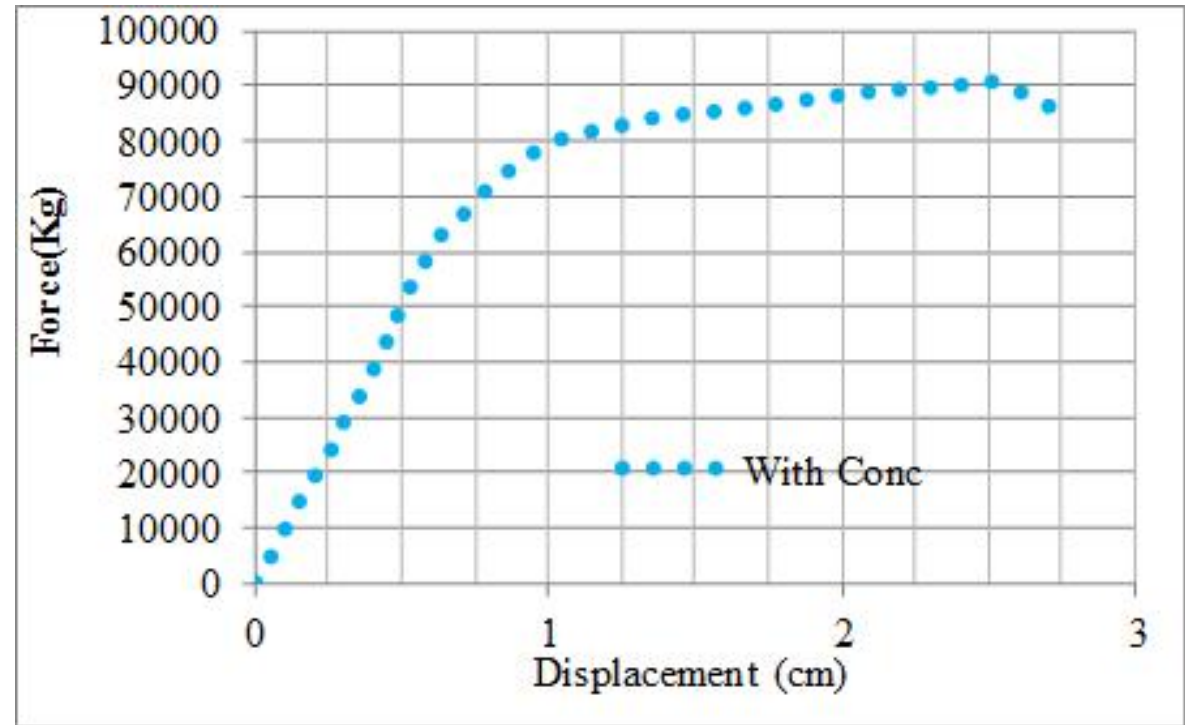

B) Sample with filler concrete

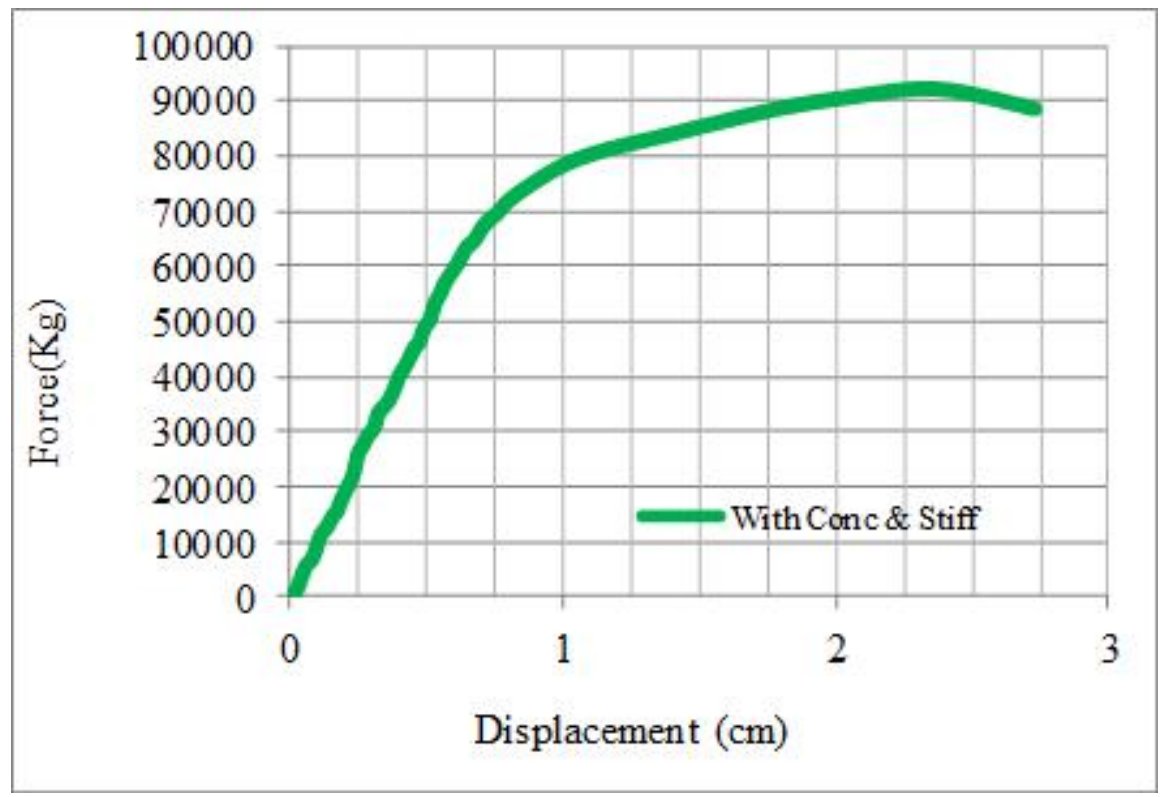

C) Sample with filler concrete and stiffener plate 


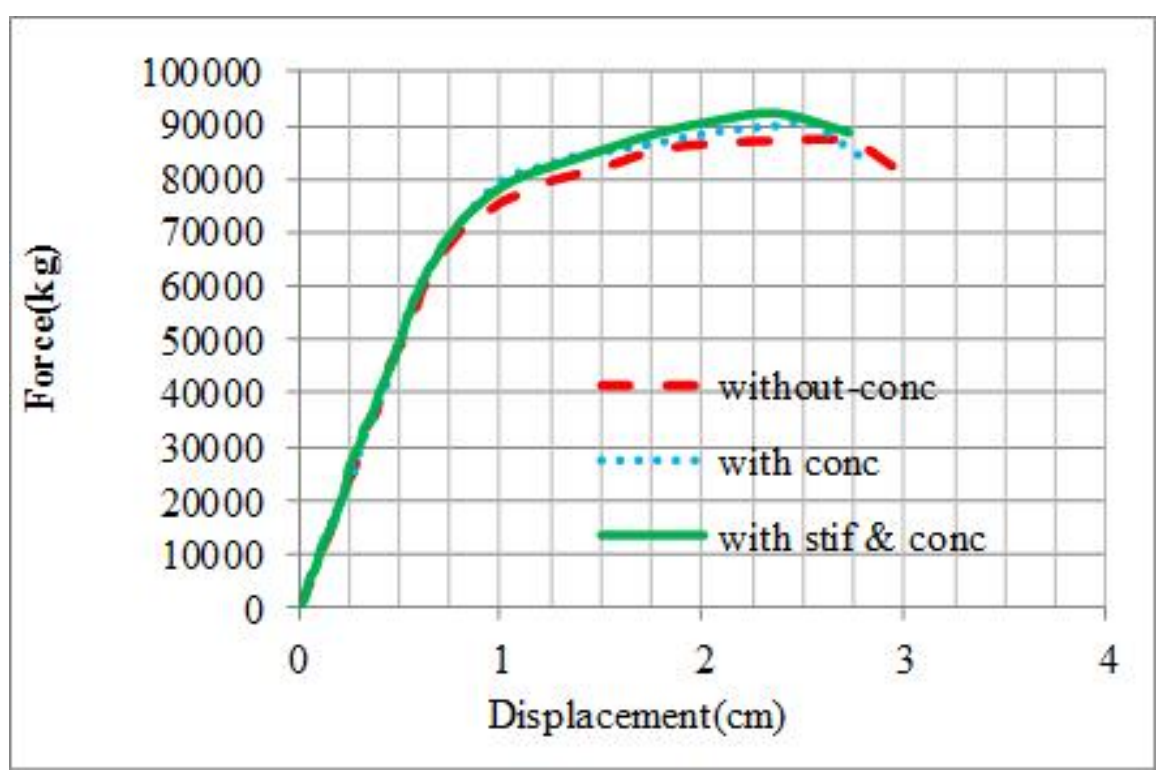

Fig.9. Force-displacement pushover curve of the samples

In the next step, all three ConXL connections were imposed to loading type 2 and hysteresis curves were plotted as shown in Figure 10. It was observed from these curves that the strength of ConXL connection without concrete filler is less than the ConXL connection with concrete filler. Also the strength of ConXL connection with concrete filler and stiffener plate is more than the other two samples.

On the other hand according to the hysteresis curves, ductility of ConXL connection without concrete filler is more than the two others. Studying the durability of concrete of all three samples, it was resulted that the durability of the connection with concrete filler and the connection with concrete filler and stiffener plate are approximately equal to each other and less than the durability of the connection without concrete filler. 


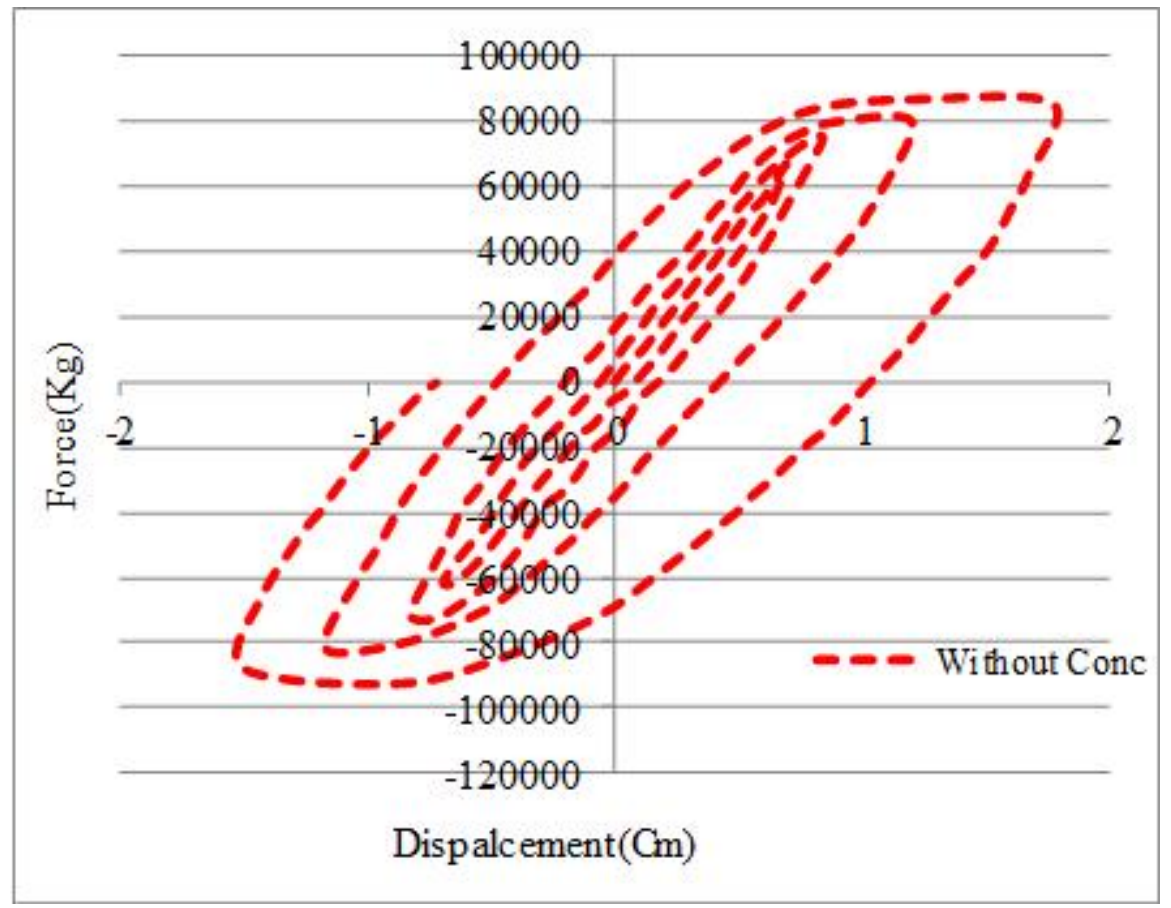

A) Sample without filler concrete

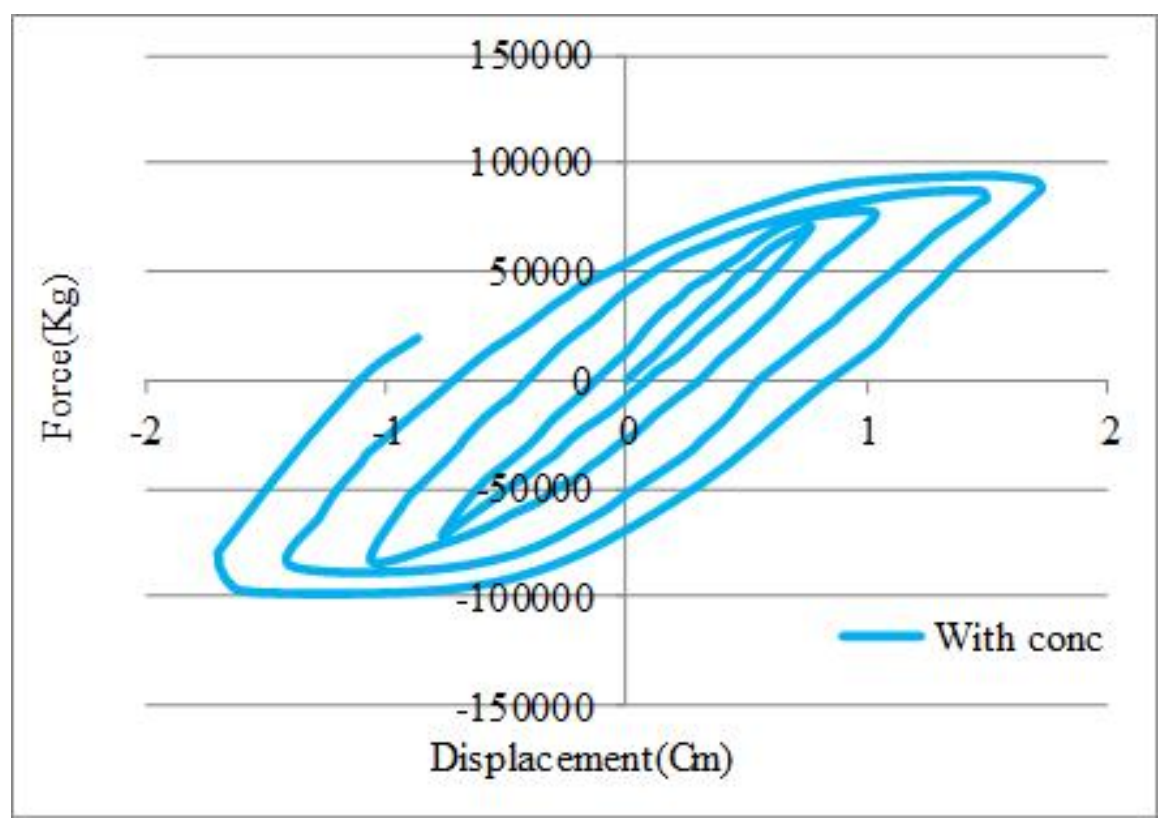

B) Sample with filler concrete 


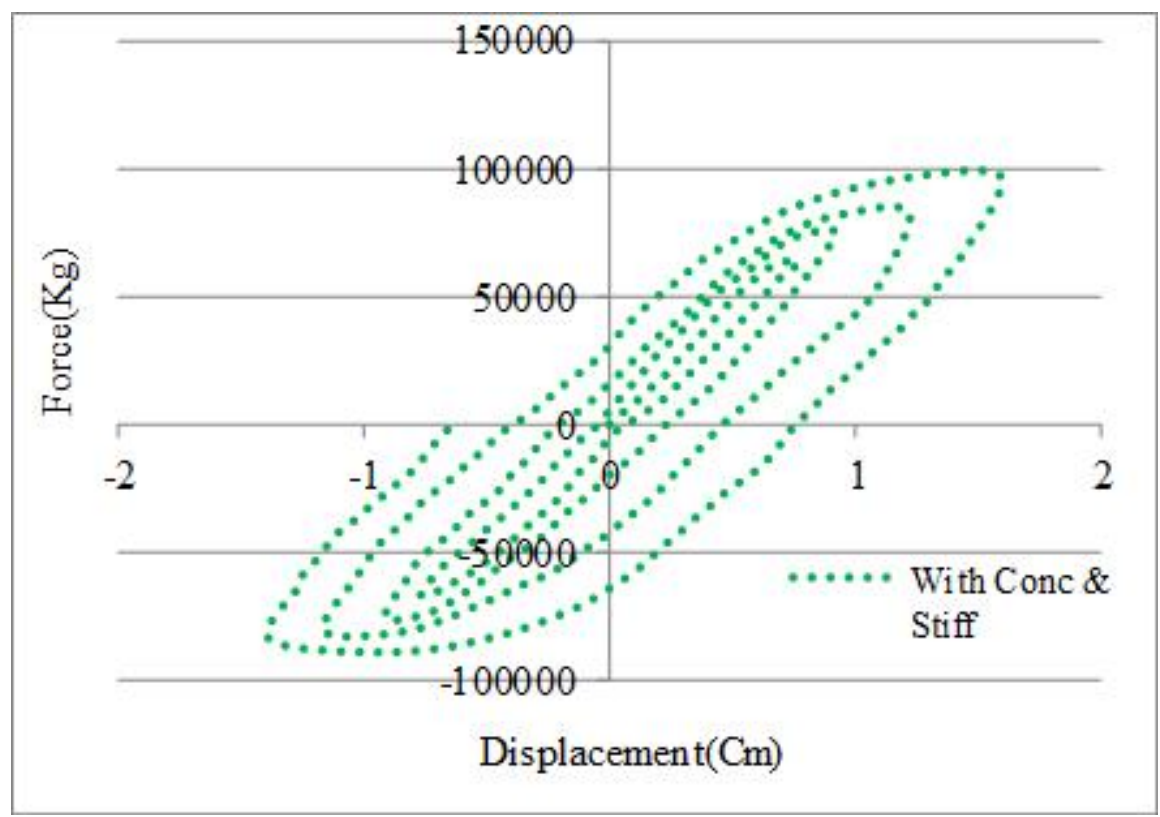

C) Sample with filler concrete and stiffener plate

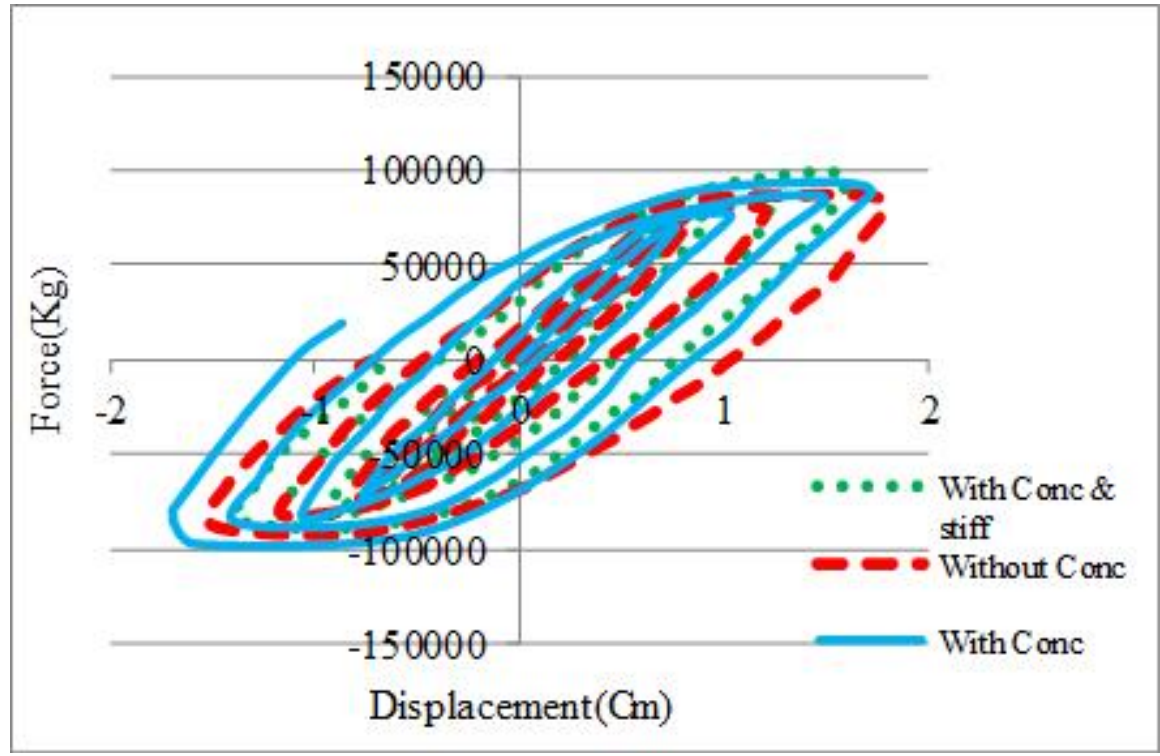

Fig.10. The hysteresis curves for the samples

\section{CONCLUSION}

The results obtained from the present study are listed as follows:

\subsection{Ductility}

The ductility of all three samples demonstrated that the ductility of ConXL connection without concrete filler is more than the two other samples, so that the ductility of connection without concrete filler was about $15 \%$ more than the ductility of connection with concrete filler; and the ductility of the connection with concrete filler was $5 \%$ more than the connection 
with concrete filler and stiffener plate.

\subsection{Strength}

It was observed from curves that the ultimate resistance of the connection with concrete filler is about $2 \%$ more than the connection with concrete filler and stiffener plate. Moreover the ultimate resistance of the connection with concrete filler was about $10 \%$ more than the connection without concrete filler.

\subsection{Buckling}

Buckling of the panel zone was not observed in any of the samples. This result indicates that the collars system act as a stiffener and prevent buckling of the panel at the connections.

\subsection{Durability}

Durability of the connections with concrete filler and with concrete filler and stiffener plate are similar. On the other hand, the durability of the connection without concrete filler was more than the two other samples. This durability reduction leads to less residual strain.

\subsection{Adhesion between concrete and steel tube}

It was observed from the results of analysis that the concrete in the samples with concrete filler protruded from the steel tube. However, they were perfectly coplanar before the loading. This indicates that the slip between the steel tube and the concrete core occurred during loading cycles.

\subsection{Energy absorption}

Hysteresis curves obtained from analysis demonstrated that the energy absorption in the connection without concrete filler is more than the two other samples.

\section{REFERENCES}

[1] Nakashima M, Roeder C.W, Maruoka Y. Steel Moment Frames For Earthquakes In United States \& Japan. Journal of Structural Engineering, 2000, 126(8), 861-868

[2] Sherman D.R. Designing With Structural Tubing. Journal of Engineering, 1996, 33(3), 101-109

[3] FEMA-355D. State of the art report on connection performance. Washington (DC): Federal Emergency Management Agency, 2000

[4] Renz B. ConXtech's Systemized Approach To Steel Construction Streamlines and 
Transforms Traditional Design And construction Processes. Journal of Modern Steel Construction, 2005

[5] ANSI/AISC 358-10 \& 358s1-11. Prequalified Connections for Special and Intermediate Steel Moment Frames for Seismic Applications, ANSI/AISC, Chicago, 2011

[6] ABAQUS version 6.12-1 user's manual. Michigan, Hibbit, Carlson \& Sorensen Inc., 2012

[7] Nateghi F, Moradi Shaghaghi T. Experimental study of composite columns behaviors. International Institute of Seismology and Earthquake Engineering, 2008

[8] Moradi Shaghaghi T, Nateghi F. Experimental Study Of Stiffener Plates Effect On The Behavior Of Steel Columns Filled With Concrete (CFST). J. Sharif Civil Engineering, 2010, $3-10$

\section{How to cite this article:}

Seyfi Azar A, Moradi Shaghaghi T. Seismic behavior of conxl connections in concrete filled steel tube columns (CFT). J. Fundam. Appl. Sci., 2017, 9(1), 217-233. 